\title{
Contamination of the environment by special purpose centrifuges used in clinical laboratories
}

\author{
GJ HARPER
}

From the Microbiological Safety Reference Laboratory, Public Health Laboratory Service, Centre for Applied Microbiology and Research, Porton Down, Salisbury

SUMMARY The generation of aerosols and the contamination of surfaces arising from the use of a number of special purpose centrifuges have been measured. Except when sealed containers were used all the equipment tested generated airborne particles and contaminated surrounding surfaces. The magnitude of this contamination was shown to be associated with several factors, and it could be considerably reduced by the use of sealed containers, and by fitting air filters. The significance of these findings and their application are discussed.

Efforts to speed up and to improve clinical laboratory procedures have led to the introduction of special purpose centrifuges designed either to eliminate tedious hand operations or to prepare "standard" preparations for processing in automated equipment. Examples include cell washing centrifuges used for carrying out Coombs' tests, centrifuges for preparing cytological specimens from body fluids and blood film spinners to prepare film for assessment by automatic image analysers. There is considerable evidence ${ }^{1-5}$ that the manipulation of fluids produces airborne particles. If the fluid being processed contains an infectious micro-organism there could be a hazard due to the aerosols in the laboratory.

Several special purpose centrifuges have been examined to assess the quantity of material produced as airborne particles and to measure surface contamination within and around the equipment.

\section{Material and methods}

EQUIPMENT TESTED

Cell washing centrifuges

1 Dupont Sorvall CW1/AF2

2 Dade C7M

3 Becton Dickinson Spectra IIa

\section{Bench Centrifuge \\ 4 Dade Immufuge}

Accepted for publication 2 March 1981

\section{Cytological Ccntrifuge}

5 Shandon-Southern Cytospin

\section{Blood Film Spinner}

6 Abbott Blood Film Spinner (part of Abbotte ADC 500).

\section{TESTING PROCEDURE}

The equipment was assembled, tested and operated in accordance with the instruction manuals provided by the manufacturers.

The tests were done inside a suitably modified Porton Class III safety cabinet (volume $0.38 \mathrm{~m}^{3}$ ). The cabinet, fitted with HEPA filters on both the air inlet and outlet, was equipped with vacuum lines to external pumps for the operation of air sampling equipment inside the cabinet. Supplies of electric power, cell washing fluid and drainage for effluent from the equipment were provided by airtight connectors passing through the wall of the cabinet. The operator wore rubber gauntlets sealed to arm holes in the front of the cabinet. The general arrangement is shown in the Figure. When the air sampling equipment was in use this created a small negative pressure $(50$ to $100 \mathrm{~Pa}$ ) in the cabinet relative to the room. The air inside the chamber could be purged between tests by means of an extract fan at a rate of $2.8 \mathrm{~m}^{3} / \mathrm{min}$. The purging fan was also used to remove formaldehyde after decontamination.

Various sampling devices (see below) were used to collect any airborne particles generated during a test. In some tests settle plates were exposed around the equipment. Surface contamination was assessed by 


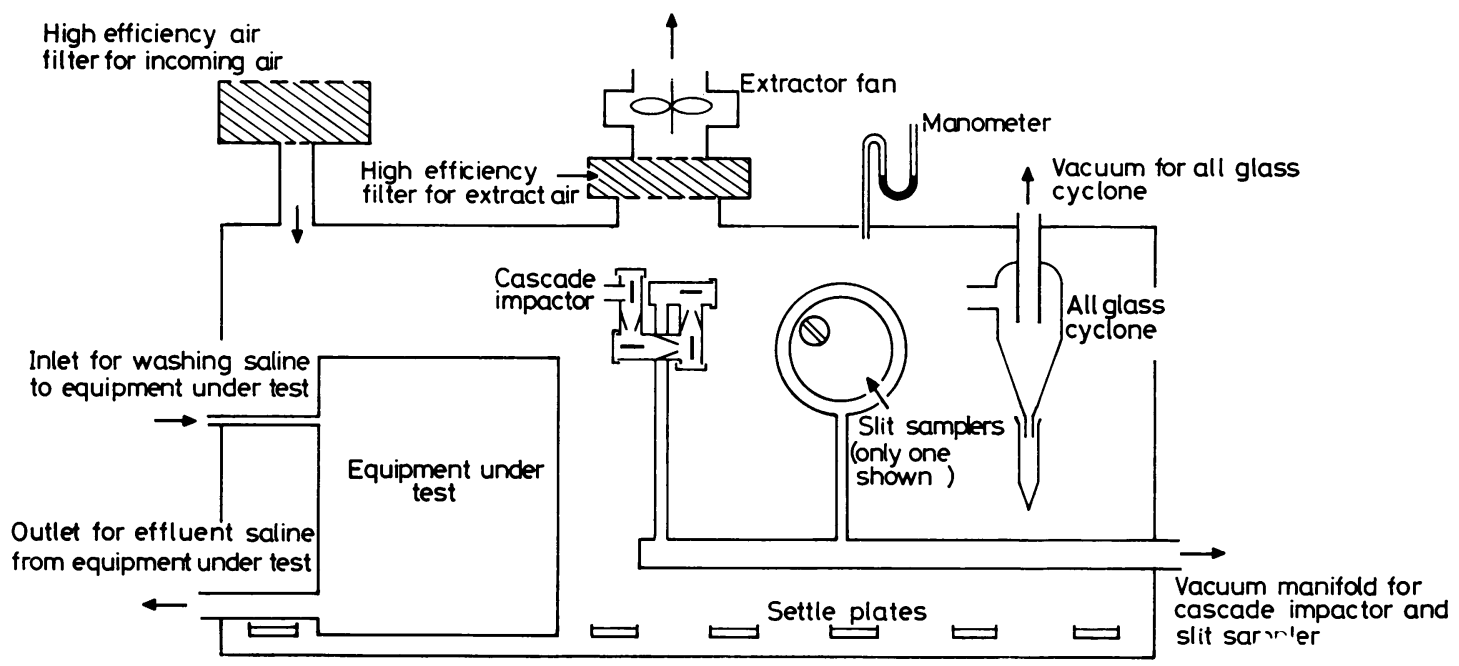

Arrangement of equipment and air samplers in the test cabinet

sampling surfaces inside and outside the equipment by using sterile cotton wool swabs moistened with distilled water. Adequate control samples of air and from surfaces were collected before each test to measure any background contamination with the test micro-organisms. The test chamber was decontaminated with formaldehyde between each test and thoroughly aired. Surfaces were then swabbed to detect any residual contamination with the test micro-organism.

\section{AIR SAMPLING EQUIPMENT}

\section{Large volume glass cyclone sampler}

This device concentrates the particles from about $0.7 \mathrm{~m}^{3} / \mathrm{min}$ of air into $1 \mathrm{ml}$ of phosphate buffer.

\section{Slit sampler}

Particles are collected directly on to the surface of nutrient agar plates at a sampling rate of 0.025 $\mathrm{m}^{3} / \mathrm{min}$.

\section{Cascade impactor 6}

Used to measure particle size by impaction on to four stages when sampling at a rate of $0.017 \mathrm{~m}^{3} / \mathrm{min}$. The collection surfaces of the slides were coated with $5 \%(\mathrm{wt} / \mathrm{vol})$ gelatin in $10 \%$ glycerol. The collected micro-organisms were recovered by dissolving the gelatin-glycerol film in phosphate buffer at $37^{\circ} \mathrm{C}$.

Test fluids and biological tracer cells

An aqueous suspension of spores of Bacillus globigii
(BG) was added to test fluids, representing as closely as possible the material usually processed in the equipment being tested, to yield a final spore concentration of between $2 \times 10^{9}$ and $1 \times 10^{10}$ per ml. The test fluids used were not the same for all the equipment; details are given separately under "Results."

\section{Culture media}

All cultures were made on the surface of preincubated plates of typtone agar. Where necessary, samples were diluted in phosphate buffer. The test microorganism produces a bright orange colony easily distinguished from any contaminating microorganism present.

\section{CALCULATION OF RESULTS}

To permit direct comparison between tests with different equipment, and for variations in the concentrations of tracer micro-organism, results of aerosol recoveries are expressed in nanolitres of test fluid recovered. This value was calculated by dividing the number of tracer cells recovered by an aerosol sampler by the number of tracer cells contained in one nanolitre of the test fluid. With the cyclone sampler used the lower level of detection is 0.001 nanolitres.

In some tests swab samples were assessed quantitatively, results being expressed in nanolitres of the test fluid recovered as for the aerosol samples; in other tests swabs were plated directly without extraction and the results are qualitative. 
Cell washing centrifuges and Dade Immufuge (1, 2, 3 and 4)

Although the Dade Immufuge differs from the three cell washing centrifuges in that it does not carry out the cell washing process automatically it is included in this group of equipment because it is described as suitable for immunohaematology tests, and is sometimes used for washing ceils.

\section{METHOD}

Twelve $12 \mathrm{~mm} \times 75 \mathrm{~mm}$ disposable glass tubes were each loaded with $0.2 \mathrm{ml}$ volumes of a mixture containing human serum and $10 \%$ by volume of a $5 \%$ ( $\mathrm{vol} / \mathrm{vol})$ suspension of washed human red cells. BG cells at a concentration of $1 \times 10^{10} \mathrm{ml}$ were present as the tracer. Thus for each test a total of $2.4 \mathrm{ml}$ of BG labelled material was processed. Cell washing was carried out using $0.85 \%$ (wt/vol) sterile sodium chloride solution.

In the tests with the Dade Immufuge the cell washing was carried out manually. After a cycle of centrifugation the plastic rotor was removed from its spindle and the supernatant fluid decanted by inverting the rotor over a beaker. The tubes were held in the rotor by plastic springs. After decanting, the sedimented cells were resuspended by flicking each tube whilst retained in the rotor. Saline $(4.5 \mathrm{ml}$ per tube) was added in two increments from a plastic squeeze bottle. The rotor was then replaced on the spindle. This cycle of operations was repeated 3 times. The decanting and resuspending operations generated splashes which were visible on the inner surface of the test chamber, the rotor and the operator's gauntlets. In some tests visible contamination was transferred by the operator's gauntlets to the lid of the centrifuge.

Tests with the Dupont Sorvall CW1/AF2 were terminated at the end of four wash cycles. This equipment does not automatically add reagents after completion of cell washing.

With both the Dade C7M and the Becton Dickinson Spectra IIa the full programme, which includes three wash cycles, the addition of Coombs' reagent and a final spin was carried out. Air samples were collected with cyclones, slit samplers and cascade impactors, settle plates were exposed, swabs were collected and assessed quantitively, and the wash fluid and tube contents were assayed for BG. Each piece of equipment was tested on either three or four separate occasions.

\section{RESULTS}

\section{Control samples}

Of 13 cyclone air samples collected before testing 10 yielded no viable BG, in the other three samples the recoveries were less than $1 \%$ of those measured during the corresponding tests.

A total of 96 surface samples were collected before testing. Of these, 87 yielded no viable BG. The recoveries from the other nine samples were less than $0.01 \%$ of those measured in the corresponding tests. These small background recoveries have been ignored in calculating the recoveries from samples collected during the tests.

\section{Recoveries from air samples}

All the equipment tested generated aerosols (Table 1) The highest levels were found using a manual process with the Dade Immufuge. This procedure also generated the largest airborne particles (Table 2)

Table 1 BG tracer recoveries by cyclone air samplers expressed as nanolitres of infected serum per millilitre of infected serum processed

\begin{tabular}{ll}
\hline Cell washing equipment & Recovered as aerosol $(\mathrm{nl} / \mathrm{ml})$ \\
\hline Dade Immufuge & $0 \cdot 6,0 \cdot 2,0 \cdot 5$ \\
Dupont Sorvall CW I/AF2 & $0 \cdot 002 *, 0 \cdot 04^{*}, 0 \cdot 06 \dagger, 0 \cdot 1 \ddagger$ \\
Dade C7M & $0 \cdot 07,0 \cdot 1,0 \cdot 1$ \\
Becton Dickinson Spectra IIa & $0 \cdot 05,0 \cdot 1,0 \cdot 1$ \\
\hline
\end{tabular}

* $54 \mathrm{ml}$ saline per wash cycle.

$\dagger 58 \mathrm{ml}$ saline per wash cycle.

$\ddagger 65 \mathrm{ml}$ saline per wash cycle.

Table 2 Percentage distributions of BG recovered from aerosols generated by cell washing equipment sampling by Cascade Impactor

\begin{tabular}{|c|c|c|c|c|c|}
\hline \multirow[t]{2}{*}{ Cascade Impactor Stage } & \multirow{2}{*}{$\begin{array}{l}\text { Size range of } \\
\text { particles collected } \\
(\mu \mathrm{m})\end{array}$} & \multicolumn{4}{|c|}{ Percentage of total collected $(\%)$} \\
\hline & & Dade Immufuge & $\begin{array}{l}\text { Dupont Sorvall } \\
C W 1 / A F 2\end{array}$ & Dade C7M & $\begin{array}{l}\text { Becton Dickinson } \\
\text { Spectra IIa }\end{array}$ \\
\hline $\begin{array}{l}1 \\
2 \\
3 \\
4 \\
\text { Mass median diameter }(\mu \mathrm{m}) \\
\text { Percentage of particles } \\
\quad<5 \mu \mathrm{m} \text { diameter }\end{array}$ & $\begin{array}{l}6 \text { to } 20 \\
2 \cdot 2 \text { to } 6 \\
1 \text { to } 3 \\
0 \cdot 5 \text { to } 1 \cdot 5\end{array}$ & $\begin{array}{l}50 \\
28 \\
12 \\
10 \\
13\end{array}$ & $\begin{array}{r}15 \\
29 \\
48 \\
8 \\
5\end{array}$ & $\begin{array}{r}3 \\
16 \\
48 \\
33 \\
2 \\
\\
84\end{array}$ & $\begin{array}{r}4 \\
44 \\
45 \\
7 \\
4\end{array}$ \\
\hline
\end{tabular}


and it is possible that the major part of the aerosol recovered in these tests was generated by the manual washing process rather than by the centrifuge. The effect of using more than the recommended volume of wash fluid was shown in tests with the Dupont/ Sorvall equipment (Table 1). Although the saline delivery valve was always set to deliver $54 \mathrm{ml}$ per wash cycle before each test, the actual volume delivered was found to vary between $54 \mathrm{ml}$ and $65 \mathrm{ml}$. Whether this day-to-day variation in the volume of wash saline delivered was a function of the particular machine used is not known.

With two of the centrifuges, the Dupont Sorvall CW1/AF2 and the Becton Dickinson Spectra IIa, little aerosol was generated during the first centrifugation which took place when the inner walls and lid of the wash chamber were dry (Table 3 ). This suggests that the primary source of the aerosol was the generation of particles from the saline wash fluid thrown to the walls of the chamber, or on to the lid by the preceding wash cycle. With the Dade C7M the aerosol recoveries were at about the same level in each of the wash cycles-indicating that in this equipment the centrifugation process produced aerosols from the material contained in the tubes, or that the aerosol was generated by the injection of the washing saline into tubes held in the rotating head. Clearly there are many ways in which aerosols can be generated in complex equipment involving centrifugation and the injection and removal of liquid.

Table 4 shows the recovery of airborne particles both in the air by slit samplers and on surfaces by settle plates. Because of the high degree of turbulence in the test chamber only the larger airborne particles would be likely to deposit on the settle plates. The results obtained show good agreement with estimates of the particle sizes made by cascade impactors (Table 2).

Table 4 BG containing particles recovered from aerosol and on settle plates

\begin{tabular}{|c|c|c|}
\hline \multirow[t]{2}{*}{ Cell washing equipment } & \multicolumn{2}{|l|}{ Particles recovered } \\
\hline & $\begin{array}{l}\text { Aerosol slit } \\
\text { sampler }\end{array}$ & $\begin{array}{l}\text { Settle plates } \\
\text { Total on three plates }\end{array}$ \\
\hline $\begin{array}{l}\text { Dade Immufuge } \\
\text { Dupont Sorvall CW1/AF2 } \\
\text { Dade C7M } \\
\text { Becton Dickinson Spectra } \\
\quad \text { Ila }\end{array}$ & $\begin{array}{l}127,727,657 \\
58,58,484,1130 \\
1061,1188,1684\end{array}$ & $\begin{array}{l}12,49,132 \\
7,0,2,0 \\
3,1,2\end{array}$ \\
\hline
\end{tabular}

\section{Surface contamination}

The results of the surface swabbing are summarised in Table 5. The surfaces of the rotor and the interior of the wash chamber were all heavily contaminated. The rotor of the Dade C7M showed much heavier contamination than the other three centrifuges. A

Table 3 Percentage of total airborne cells and particles recovered during various stages of the operating cycles of cell washing equipment

\begin{tabular}{|c|c|c|c|c|c|c|c|c|}
\hline \multirow[t]{2}{*}{ Operation } & \multicolumn{2}{|c|}{ Dade Immufuge } & \multicolumn{2}{|c|}{$\begin{array}{l}\text { Dupont Sorvall } \\
C W 1 / A F 2\end{array}$} & \multicolumn{2}{|c|}{ Dade $C 7 M$} & \multicolumn{2}{|c|}{$\begin{array}{l}\text { Becton Dickinson } \\
\text { Spectra IIa }\end{array}$} \\
\hline & Cells & Particles & Cells & Particles & Cells & Particles & Cells & Particles \\
\hline Ist wash cycle & 22 & 22 & $<1$ & $<1$ & 27 & 35 & 1 & 1 \\
\hline 2nd wash cycle & 37 & 41 & 14 & 24 & 33 & 34 & 17 & 41 \\
\hline 3rd wash cycle & 30 & 25 & 28 & 40 & 21 & 19 & 41 & 42 \\
\hline 4th wash cycle & & & 47 & 35 & & & & \\
\hline Add Coombs' reagent & & & & & 7 & 5 & 24 & 14 \\
\hline Final spin & & & & & 6 & 6 & 11 & 2 \\
\hline Open lid & 11 & 12 & 11 & $<1$ & 6 & 1 & 6 & $<1$ \\
\hline
\end{tabular}

Table 5 Recovery of BG from surfaces of cell washing centrifuges expressed as nanolitres recovered per millilitre of infected serum processed (means of 3 or 4 tests)

\begin{tabular}{lcccc}
\hline Surface & Dade Immufuge & $\begin{array}{l}\text { Dupont Sorvall } \\
\text { CWI/AF2 }\end{array}$ & $\begin{array}{c}\text { Dade C7M } \\
\text { Spectra IIa }\end{array}$ \\
\hline Rotor & 23 & 3 & 33 \\
Wash chamber walls & 620 & $23(288)$ & 1280 & 274 \\
Wash chamber lid & 455 & $238(680)$ & 660 & $0 \cdot 002$ \\
Outside of case & 7 & $0 \cdot 02$ & $0 \cdot 02$ & 02 \\
Operator's gauntlets & 60 & $0 \cdot 01$ & $0 \cdot 001$ & $<\cdot 03$ \\
Inside of test & 103 & $0 \cdot 01$ & $<0 \cdot 001$ \\
chamber window & & & \\
\hline
\end{tabular}

( ) = tests with larger volumes of saline. 
few colonies were found on the settle plates exposed around the base of the centrifuges (Table 4). The manual washing procedure carried out in the Dade Immufuge resulted in contamination of the outside of the centrifuge case, the operators' gauntlets and the window of the test chamber. The other three centrifuges showed little or no contamination of these sites.

\section{Wash liquid and the contents of the tubes}

Effluent from the cell washing equipment was cultured and found to be heavily contaminated with tracer cells. At the end of the Coombs' procedure the tubes containing the washed cells were always heavily contaminated with tracer cells.

\section{Cytological Centrifuge (5)}

The Shandon-Southern Cytospin* is designed for the rapid and standardised centrifugation of suspensions of biological cells, or other suspended particles, directly on to microscope slides. The machine can be used either with 12 moulded plastic sample chambers closed with plastic caps with vent holes or with up to six sealed containers specially designed to protect the operator from aerosols.

Under the influence of centrifugal force the sample is driven through the outlet port of the sample chamber and the cells are deposited on a small defined area of a microscope slide. The suspending fluid is absorbed by a filter card, or cards, positioned between the sample chamber and the slide. The cards have a circular hole corresponding in size and position with the outlet port of the sample chamber.

Aerosol generation and surface contamination was assessed using both the unsealed and sealed

*Since this work was completed Shandon Southern Products Ltd have re-designed the Cytospin. The new equipment (Cytospin 2) has a sealed head in place of the sealed chambers used in the earlier model tested. containers filled with different volumes of test suspension.

\section{METHOD}

For each test two sample chambers were used. Two rotors were tested, one with drainage holes in the base, and the other without drainage. The test chambers were filled with volumes ranging from $0.7 \mathrm{ml}$ to $2.5 \mathrm{ml}$ of $10 \%$ ( $\mathrm{vol} / \mathrm{vol}$ ) human plasma containing $5 \times 10^{9} \mathrm{BG}$ spores per $\mathrm{ml}$.

Each test load was centrifuged at $1500 \mathrm{rpm}$ for $10 \mathrm{~min}$. When the outer shield warning light showed that it was safe to do so the stainless steel lid was removed. When sealed containers were used they were removed from the rotor and the caps unscrewed close to the air sampling equipment.

Air samples were collected using cyclones and slit samplers, settle plates were exposed, and swabs were collected. These were assessed qualitatively.

\section{RESULTS}

\section{Control samples}

Of 20 air samples collected before testing 12 were negative for BG, the other 8 samples contained less than $1 \%$ of the numbers of $\mathrm{BG}$ recovered during the corresponding tests. Twenty-eight of 39 surface samples were sterile - the remainder yielded less than $1 \%$ of the numbers recovered during the corresponding tests. These background counts have been ignored in calculating the recoveries from the samples collected during tests.

\section{Recoveries from air samples}

These are shown in Table 6. The use of the unsealed plastic chambers demonstrated the generation of aerosols in all of the tests. The volume of test suspension recovered from the air was directly related to the volume contained in the sample chambers. Opening the Cytospin at the end of the

Table 6 BG tracer recoveries by cyclone air samplers from Shandon-Southern Cytospin expressed as nanolitres of infected serum per millilitre of infected plasma processed

\begin{tabular}{|c|c|c|c|c|c|c|c|}
\hline \multirow[t]{2}{*}{ Test no } & \multirow{2}{*}{$\begin{array}{l}\text { Sample } \\
\text { chamber }\end{array}$} & \multirow[t]{2}{*}{ Rotor } & \multirow{2}{*}{$\begin{array}{l}\text { Volume in } \\
\text { sample } \\
\text { chamber }(\mathrm{ml})\end{array}$} & \multirow{2}{*}{$\begin{array}{l}\text { No of filter } \\
\text { cards }\end{array}$} & \multicolumn{3}{|c|}{ Aerosol recovered $(n l / m l)$} \\
\hline & & & & & $\begin{array}{l}\text { During } \\
\text { spinning }\end{array}$ & $\begin{array}{l}\text { Opening } \\
\text { shield }\end{array}$ & $\begin{array}{l}\text { Opening } \\
\text { sealed container }\end{array}$ \\
\hline 1 & Unsealed & with & $0 \cdot 7$ & 1 & $0 \cdot 02$ & $0 \cdot 001$ & \\
\hline 2 & plastic & drainage & $1 \cdot 0$ & 2 & 0.07 & 0.004 & \\
\hline 3 & & holes & $1 \cdot 5$ & 2 & 0.90 & 0.03 & \\
\hline 4 & & & $2 \cdot 0$ & 2 & $1 \cdot 38$ & 0.02 & \\
\hline 5 & & & $2 \cdot 5$ & 2 & $2 \cdot 17$ & $0 \cdot 13$ & \\
\hline 6 & & no & $1 \cdot 5$ & 2 & $0 \cdot 90$ & 0.07 & \\
\hline 7 & & drainage holes & $2 \cdot 5$ & 2 & $2 \cdot 73$ & $0 \cdot 21$ & \\
\hline 8 & Sealed & with & $1 \cdot 0$ & 2 & $<0.001$ & $<0.001$ & $0 \cdot 31$ \\
\hline 9 & & drainage & $1 \cdot 5$ & 2 & $<0.001$ & $<0.001$ & $<0.001$ \\
\hline 10 & & holes & $2 \cdot 5$ & 2 & $<0.001$ & $<0.001$ & $0 \cdot 20$ \\
\hline
\end{tabular}


centrifugation also gave rise to aerosols-this was always at a much lower level than that detected whilst the centrifuge was running. The use of a rotor without drainage holes did not show any difference when compared with the rotor with drainage holes.

When the sealed containers were used no measurable airborne contamination $(<0.001$ nanolitres $)$ was detected during centrifugation or the removal of the shield. On two out of three tests opening the sealed container did result in the liberation of airborne particles.

Slit sampler plates from tests with unsealed chambers yielding sufficient colonies to justify analysis (Table 7) show that about $94 \%$ of the airborne material recovered during the ten minute centrifugation cycle was generated within the first two minutes.

\section{Surface contamination}

The use of unsealed plastic chambers caused gross contamination of the rotor and the inner surfaces of the shield (Table 8). Some contamination was also found on the top surface of the Cytospin cabinet. Settle plates showed contamination of the base of the test chamber-the numbers of colonies found increased with the volume of charging in the sample chamber.

When sealed containers were used some contamination was found when swabs and settle plates were collected after the sealed containers were opened. Swabs collected before opening the sealed containers were uniformly negative for BG.

Although the slides, filter cards and test chambers were not sampled these are all potential sources of contamination. These items should be handled with great care to prevent contamination of the operator and the environment.

\section{Blood Film Spinner (6)}

This centrifuge is part of the Abbott ADC 500, an automated system for the microscopical examination of stained blood films. Blood placed on a glass slide held on a platen is centrifuged rapidly with the

Table 7 Airborne particles recovered by slit samplers during operation of the Shandon-Southern Cytospin centrifuge using unsealed sample chambers

\begin{tabular}{|c|c|c|c|c|c|c|}
\hline \multirow{2}{*}{$\begin{array}{l}\text { Time of } \\
\text { spinning } \\
\text { (min) }\end{array}$} & \multicolumn{6}{|c|}{ Percentage of total particles recovered during 10 minutes cer.trifugation } \\
\hline & Test 2 & Test 3 & Test 4 & Test 6 & Test 7 & Means \\
\hline 0 to 1 & 88 & 69 & 88 & 76 & 66 & 77 \\
\hline 1 to 2 & 12 & 25 & 8 & 17 & 24 & 17 \\
\hline 2 to 3 & & & & 4 & 8 & 2 \\
\hline 3 to 4 & & 2 & & & 1 & 1 \\
\hline 4 to 5 & & 2 & 2 & & 1 & 1 \\
\hline 5 to 6 & & & 2 & 2 & & 1 \\
\hline 6 to 7 & & 2 & & $\overline{1}$ & & 1 \\
\hline 7 to 8 & & & & & & 0 \\
\hline 8 to 9 & & & & & & $\mathbf{0}$ \\
\hline 9 to 10 & & & & & & 0 \\
\hline Total no & & & & & & \\
\hline $\begin{array}{l}\text { of particles } \\
\text { recovered in } 10 \mathrm{mins}\end{array}$ & 493 & 1798 & 1421 & 2900 & 6554 & \\
\hline
\end{tabular}

Table 8 Recovery of BG from surfaces of Shandon-Southern Cytospin by swabbing and by settle plates

\begin{tabular}{|c|c|c|c|c|c|c|c|c|c|}
\hline \multirow{2}{*}{$\begin{array}{l}\text { Test } \\
\text { no }\end{array}$} & \multirow{2}{*}{$\begin{array}{l}\text { Sample } \\
\text { chamber }\end{array}$} & \multirow[t]{2}{*}{ Rotor } & \multirow{2}{*}{$\begin{array}{l}\text { Volume in } \\
\text { sample } \\
\text { chamber } \\
(\mathrm{ml})\end{array}$} & \multirow{2}{*}{$\begin{array}{c}\text { No of } \\
\text { filter } \\
\text { cards }\end{array}$} & \multicolumn{4}{|c|}{ BG colonies per swab } & \multirow{2}{*}{$\begin{array}{l}\text { BG colonies } \\
\text { on } \\
\text { six } \\
\text { settle } \\
\text { plates }\end{array}$} \\
\hline & & & & & Rotor & $\begin{array}{l}\text { Lid of } \\
\text { shield }\end{array}$ & $\begin{array}{l}\text { Base of } \\
\text { shield }\end{array}$ & $\begin{array}{l}\text { Surface of } \\
\text { Cytospin } \\
\text { base }\end{array}$ & \\
\hline 1 & & & $0 \cdot 7$ & 1 & CONF & CONF & 311 & 0 & 3 \\
\hline 2 & Unsealed & with & $1 \cdot 0$ & 2 & CONF & CONF & CONF & 39 & 18 \\
\hline 3 & plastic & draınage & $1 \cdot 5$ & 2 & CONF & CONF & CONF & 16 & 33 \\
\hline 4 & & holes & $2 \cdot 0$ & 2 & CONF & CONF & CONF & 22 & 22 \\
\hline 5 & & & $2 \cdot 5$ & 2 & CONF & CONF & CONF & 24 & 167 \\
\hline 6 & & no & $1 \cdot 5$ & 2 & CONF & CONF & CONF & 1 & 23 \\
\hline 7 & & $\begin{array}{l}\text { drainage } \\
\text { holes }\end{array}$ & $2 \cdot 5$ & 2 & CONF & CONF & CONF & 1 & 167 \\
\hline 8 & & with & $1 \cdot 0$ & 2 & 0 & 0 & 0 & $0\left(55^{*}\right)$ & 7 \\
\hline 9 & Sealed & drainage & $1 \cdot 5$ & 2 & 0 & 0 & 0 & $0\left(0^{*}\right)$ & 0 \\
\hline 10 & & holes & $2 \cdot 5$ & 2 & 0 & 0 & 0 & $10^{*}$ & 2 \\
\hline
\end{tabular}

* Swabs collected after opening sealed containers.

CONF := Confluent growth of BG. 
object of leaving a thin uniform film on the slide; excess blood is thrown into a catchment bowl surrounding the platen. In the "Automatic" mode the length of spin is controlled by a light sensor, in the "Manual" mode the time of spinning can be varied between 0.3 and 2.5 seconds. A safety interlock prevents the spinner being operated unless the spring loaded lid is held down in the fully closed position. With the lid in this position a rubber gasket on the underside of the lid seals on to the metal rim of the spin chamber. It is assumed that the spin chamber is effectively sealed during spinning.

At the end of the centrifugation cycle, indicated by a warning light, the spring loaded lid is released-it will only partially open and remains locked in this position for approximately 5 seconds before it can be fully opened. A warning light indicates when it is safe to do so. A fan extracts air from the rear of the spin chamber and discharges it through perforations in the base of the spinner. During the spinning cycle the air extract duct from the spin chamber is automatically closed. A small HEPA filter is fitted in a compartment between the spin chamber and the extract fan. The filter fitted to the equipment tested was stated to have the following characteristics: penetration of DOP $<0.03 \%$ : pressure drop $<374$ $\mathrm{Pa}$ at a flow rate of $0.5 \mathrm{~m}^{3} / \mathrm{min}$.

To assess the maximum hazard from this type of equipment some tests were done with the HEPA filter removed. Both the Manual and Automatic modes were used to assess aerosol generation and surface contamination.

\section{METHOD}

After placing a clean slide on the platen $0.2 \mathrm{ml}$ of human blood containing about $3 \times 10^{9}$ viable BG per $\mathrm{ml}$ was pipetted on to the centre of the slide by means of an Oxford pipettor. The apparatus was then operated in the appropriate mode, controlling the opening of the lid by use of the warning light.

Air samples were collected using cyclones and slit samplers, and swabs were assessed qualitatively. Settle plates were not used.

\section{RESULTS}

\section{Control samples}

Of 36 control air samples collected by slit samplers 33 were sterile and 3 samples yielded one colony per plate. Control cyclone samples collected before each day's tests were all sterile. None of the eight control swabs collected from surfaces before testing yielded any viable $\mathrm{BG}$.

\section{Recoveries from air samples}

Aerosol recoveries for each test are shown in Table 9.

Airborne material was recovered from all the tests. When the equipment was operated without the air filter the volume of test fluid recovered in the air samples was similar to that found during cell washing in the Dade Immufuge (see Table 1).

With the HEPA filter in place cyclone recoveries were about $5 \%$ of those without the filter and these results were confirmed by the slit samplers. Why the airborne contamination was not reduced by a factor greater than that found could be due to several factors. First, the filter used may have leaked or the sealing of the filter in its chamber may not have been airtight. Secondly the act of pipetting blood on to the slide, although carried out very carefully, may have been responsible for some contamination of the air inside the test chamber. third factor to be considered is the possibility of escape of airborne particles from the spin chamber due to either leakage round the lid sealing gasket, or to the abrupt opening of the spin chamber lid at the end of the spinning cycle. In tests with and without the filter in place the recoveries of airborne material measured with both the cyclone and the slit samplers were lowest when using the maximum spinning time (manual setting 10). No obvious explanation can be offered for this finding.

\section{Surface contamination}

The lid of the spin chamber and the interior of the filter chamber were heavily contaminated when sampled after processing six samples (Table 10).

Table 9 Abbott Blood Film Spinner: Recovery of BG by cyclone and slit samplers

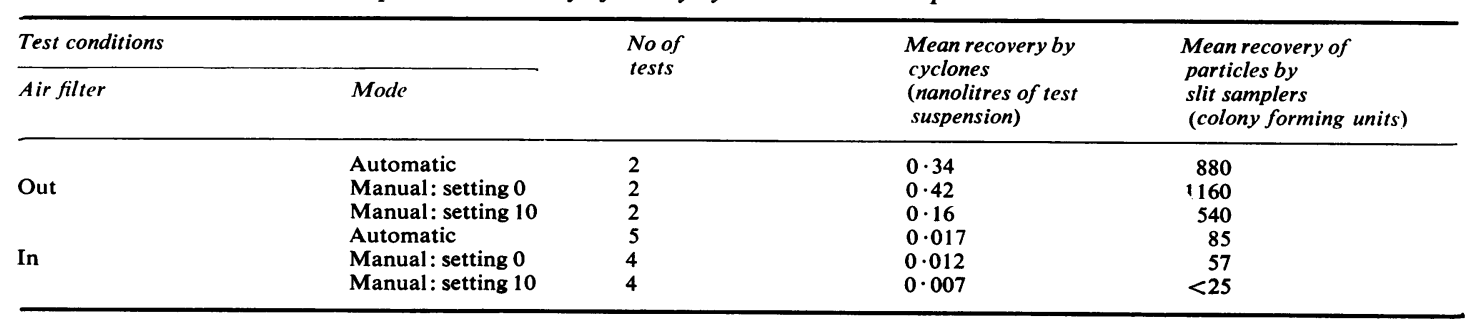


Table 10 Recovery of BG from surfaces of Abbott Blood Film Spinner: BG colonies per swab

\begin{tabular}{|c|c|c|c|c|c|}
\hline Test Numbers & & $\begin{array}{l}\text { Lid of spin } \\
\text { chamber }\end{array}$ & $\begin{array}{l}\text { Rim of spin } \\
\text { chamber }\end{array}$ & $\begin{array}{l}\text { Platform } \\
\text { round } \\
\text { spin chamber }\end{array}$ & $\begin{array}{l}\text { Inside } \\
\text { filter } \\
\text { chamber }\end{array}$ \\
\hline \multirow[t]{2}{*}{1 to 7} & Before tests & 0 & 0 & 0 & \\
\hline & After tests & CONF & 13 & 5 & \\
\hline \multirow[t]{2}{*}{8 to 13} & Before tests & 0 & 0 & 0 & \\
\hline & After tests & CONF & 0 & 38 & CONF \\
\hline \multirow[t]{2}{*}{14 to 19} & Before tests & 0 & 0 & 0 & \\
\hline & After tests & CONF & 0 & 0 & CONF \\
\hline
\end{tabular}

CONF $=$ Confluent growth of BG.

Some contamination at a much lower level was also found on the outer rim of the spin chamber and on the platform outside the spin chamber.

Blood deposited on the plastic spin chamber liner dried and then flaked off as "crumbs." Some of these large particles of dried blood were found under the plastic liner, and when the filter was not in place were found in the filter chamber. These observations were made after processing six samples. If, as recommended, the plastic liner is only replaced after processing 50 samples larger quantities of dried blood could be present in the equipment.

\section{Discussion}

All of the equipment tested produced aerosols when operated according to the manufacturers instructions with test fluids similar to those used in clinical laboratories. The use of spores suspended in water or broth would most probably have produced more airborne particles as studies with contaminated blood $^{7}$ demonstrated that it was difficult to recover airborne particles even after vigorous action, such as shaking blood to create a foam, or shattering bottles by dropping on to the floor from a height of $2 \mathrm{~m}$.

The use of sealed containers in the ShandonSouthern Cytospin and a HEPA filter in the Abbott Blood Film Spinner either eliminated or significantly reduced the airborne contamination. Introduction of these safety features by the manufacturers is a noteworthy advance. Building safety into equipment rather than having to modify the equipment after purchase is a sound policy and should be borne in mind by prospective purchasers of laboratory equipment.

The importance of operating equipment within the limits laid down by the manufacturers is illustrated in the tests with the Dupont Sorvall CW1/AF2 centrifuge and the Shandon-Southern Cytospin. An increase in the volume of the washing saline used in the CW1/AF2 centrifuge from the recommended volume of $54 \mathrm{ml}$ per cycle to $65 \mathrm{ml}$ per cycle resulted in a twentyfold increase in the number of airborne particles generated in a standard test procedure (Table 4). Although the manufacturers of the Shandon-Southern Cytospin recommended maximum volumes for processing in unsealed and sealed containers, volumes in excess of these amounts were included in the tests as it is physically possible to use larger volumes than the recommended maxima. Using the unsealed containers the aerosol recoveries and surface contamination were directly related to the volume contained in the sample container (Tables 6 and 8). No aerosol was detected when using sealed containers irrespective of the volume processed.

The need to open sealed containers, such as those used in the Shandon-Southern Cytospin, inside a microbiological safety cabinet, as recommended in the Howie Code of Practice, ${ }^{8}$ is clearly shown in Table 6. Although no aerosol was detected during centrifugation opening of the containers released aerosols into the environment.

In the tests with the cell washing centrifuges estimates were made of the size distribution of the airborne particles. Table 2 shows that appreciable proportions of these particles were below $5 \mu \mathrm{m}$ in diameter and therefore in the size range capable of penetrating, and being retained in the lower respiratory tract.

Contamination of surfaces in and around equipment was a consistent finding. The use of sealed containers in the Shandon-Southern Cytospin was effective in eliminating this form of contamination. Because of the high levels of surface contamination found in these tests, laboratories should give consideration to regular decontamination of equipment, to the wearing of gloves and to exercising care in the handling and disposal of waste materials such as cell washing fluid, filter cards, spin chamber liners and other items which may have been in contact with specimens. It is recommended that possibly contaminated fluids, such as the effluent from cell washing centrifuges, should be collected into a closed container vented by an air filter preferably containing a suitable disinfectant. The container and contents should be autoclaved at the 
end of each working day before discarding the contents. The common practice of discharging such effluents into an open container or into a laboratory sink is a potential hazard.

Although in principle it is undesirable to accept the presence of any airborne particles containing infective material whether the levels of airborne contamination measured in the tests reported here represent a hazard in clinical laboratories depends on various factors. These include (a) the probability of having infective material in the sample being processed, (b) the nature and concentration of the infective agent, (c) the dose of the infective agent required to infect man by the respiratory route, (d) the size of the airborne particles, (e) the volume of the room in which the equipment is housed, and (f) the ventilation rate of the room. A full assessment of risk requires information on all these factors; this is rarely available.

The counsel of perfection is that all aerosol generating equipment should be contained within suitable microbiological safety cabinets. There are a number of special safety cabinets available for housing aerosol generating equipment. ${ }^{9}$ This policy of containment is undoubtedly necessary when high risk material, such as cultures of Category A and B pathogens ${ }^{8}$ or specimens suspected of containing them, are being processed. However, it is not practical to enclose all equipment used in clinical laboratories within microbiological safety cabinets. For instance, much of the routine work in clinical chemistry and haematology laboratories is carried out in complex automated or semi-automated equipment capable of processing large numbers of samples each day. There has been some concern about the transmission of hepatitis $\mathrm{B}$ virus by the aerosol route in these laboratories. Recent studies ${ }^{10,11}$ strongly suggest that the principal route of infection with this virus is by the introduction of infected blood via parenteral routes and that respiratory infection is of minor importance. Therefore, there is little justification for recommending the need to enclose this type of equipment within microbiological safety cabinets when used for routine clinical work. However, as discussed elsewhere in this paper, even if there is no demonstrable aerosol hazard it is still necessary to take adequate precautions to prevent infection from handling contaminated equipment, specimen containers, and from waste materials. These vehicles of infection are all too often overlooked.

All the equipment used in a laboratory does not carry the same risk of contaminating the environment. A recent study ${ }^{12}$ showed that there was little hazard from aerosols generated by several pieces of automated equipment used by biochemists. Unpublished work carried out in the author's laboratory showed no detectable aerosol hazard arising from the use of an automated dilution dispensing system. However, both of these studies demonstrated contamination of surfaces by splashing. It was a recommendation of the Howie Committee that "assessment of the microbiological safety and suitability of new types of equipment before they were introduced into laboratory and hospital work" should be included in the Howie Code ${ }^{13}$. This recommendation was not implemented. Nevertheless, this paper and the work of Newsom and Matthews ${ }^{12}$ demonstrate the need for this kind of assessment to assist those responsible for assessing safety, and for the drawing up of codes of practice for use in clinical laboratories.

Thanks are due to the Scientific and $j$ Technical Branch of the Department of Health and Social Security for financial support in carrying out some of this work.

\section{References}

1 Wedum AG. Bacteriological safety. Am J Public Health $1953 ; 43: 1428-36$.

${ }^{2}$ Chatigny MA. Protection against infection in the microbiological laboratory: devices and procedures. Adv Appto Microbiol 1961;3:131-92.

${ }^{3}$ Kenny MT, Sabel FL. Particle size distribution of Serratide marcescens aerosols created during common laboratory? techniques and simulated accidents. Applied Microbiology 1968;16:1146-50.

${ }^{4}$ Darlow HM. Safety in the microbiological laboratory: an introduction. In: Shapton DE, Board RG, eds. Safety in microbiology. London and New York: Academic Press, 1972:1-20.

${ }^{5}$ Stern EL, Johnson JW, Vesley D, Halbert MM, Williams LE, Blume P. Aerosol production associated with clinical laboratory procedures. Am J Clin Pathol 1974;62: 591-600.

- May KR. The cascade impactor, an instrument for sampling coarse aerosols. J Sci Instr 1945;22:187-95.

${ }^{7}$ MRC Working Party on Haemodialysis. Experimental studies on environmental contamination with infected blood during haemodialysis. J Hyg (Camb) 1975;74: 133-48.

${ }^{8}$ Howie JW, chairman. A code of practice for the prevention of infection in clinical laboratories and postmortem rooms. (DHSS, Working Party.) London: HMSO, 1978.

- Evans CGT, Harris-Smith R, Stratton JED. The use of safety cabinets for the prevention of laboratory acquired infection. In: Shapton DE, Board RG, eds. Safety in microbiology. London and New York: Academic Press, 1972:21-36.

10 Petersen NJ, Bond WW, Favero MS. Air sampling for hepatitis B surface antigen in a dental operatory. $J \mathbf{A m}$ Dent Assoc 1979;99:465-7.

11 Lauer JL, Van Drunen NA, Washburn JW, Balfour HH. Transmission of hepatitis B virus in clinical laboratory areas. J Infect Dis 1979;140:513-6.

12 Newsom SWB, Matthews J. A microbiological survey of automated biochemical machines. J Clin Pathol 1980; 33:566-70. 
${ }^{13}$ Howie JW, Collins $\mathrm{CH}$. The Howie Code for preventing infection in clinical laboratories; comments on some general criticisms and specific complaints. $\mathrm{Br} \mathrm{Med} J \mathrm{1980}$; i:1071-4.
Requests for reprints to: Mr GJ Harper, Microbiological Safety Reference Laboratory, Public Health Laboratory Service, Centre for Applied Microbiology and Research, Porton Down, Salisbury, England. 